\title{
EULAR points to consider for minimal reporting requirements in synovial tissue research in rheumatology
}

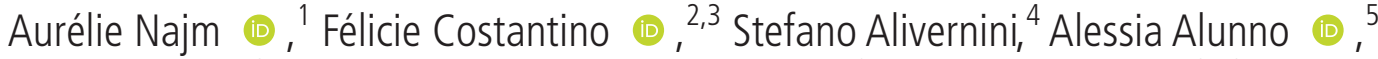 \\ Elettra Bianchi, ${ }^{6}$ Jacqueline Bignall, ${ }^{7}$ Brendan Boyce, ${ }^{8}$ Juan D Canete (1), 9,10

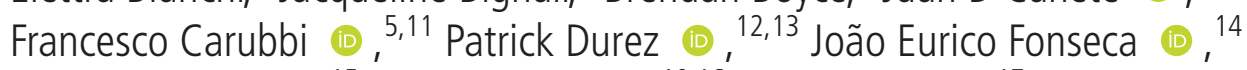 \\ Søren Andreas Just, ${ }^{15}$ Raquel Largo (10, ${ }^{10,16}$ Antonio Manzo, ${ }^{17}$ Mark Maybury, ${ }^{18}$ \\ Esperanza Naredo, ${ }^{19}$ Carl Orr, ${ }^{20,21}$ Costantino Pitzalis @i , ${ }^{22}$ Felice Rivellese, ${ }^{22}$ \\ Vasco C Romão (1) , ${ }^{14}$ Jef van Rompay, ${ }^{23}$ Sander W Tas, ${ }^{24}$ Douglas J Veale 다, ${ }^{20,21}$ \\ Maria-Antonietta D'Agostino (i), ${ }^{2,4}$ Andrew Filer ${ }^{18}{ }^{18}$
}

\begin{abstract}
Handling editor Josef $S$ Smolen

- Additional supplemental material is published online only. To view, please visit the journal online (http://dx.doi. org/10.1136/annrheumdis2021-221875).
\end{abstract}

For numbered affiliations see end of article.

Correspondence to Dr Aurélie Najm, Institute of Infection, Immunity and Inflammation, University of Glasgow College of Medical Veterinary and Life Sciences, Glasgow, Glasgow, UK; aurelie.najm@glasgow.ac.uk

$M-A D$ and $A F$ are joint senior authors.

Received 17 November 2021 Accepted 20 January 2022

Check for updates

(C) Author(s) (or their employer(s)) 2022. No commercial re-use. See rights and permissions. Published by BMJ.

To cite: Najm A,

Costantino $\mathrm{F}_{\text {, }}$

Alivernini $S$, et al.

Ann Rheum Dis Epub ahead

of print: [please include Day

Month Year]. doi:10.1136/

annrheumdis-2021-221875

\section{ABSTRACT}

Background Synovial tissue research has become widely developed in several rheumatology centres, however, large discrepancies exist in the way synovial tissue is handled and, more specifically, how data pertaining to biopsy procedure, quality check and experimental results are reported in the literature. This heterogeneity hampers the progress of research in this rapidly expanding field. In that context, under the umbrella of European Alliance of Associations for Rheumatology, we aimed at proposing points to consider (PtC) for minimal reporting requirements in synovial tissue research.

Methods Twenty-five members from 10 countries across Europe and USA met virtually to define the key areas needing evaluation and formulating the research questions to inform a systematic literature review (SLR). The results were presented during a second virtual meeting where PtC were formulated and agreed.

Results Study design, biopsy procedures, tissue handling, tissue quality control and tissue outcomes (imaging, DNA/RNA analysis and disaggregation) were identified as important aspects for the quality of synovial tissue research. The SLR interrogated four databases, retrieved 7654 abstracts and included 26 manuscripts. Three OPs and nine PtC were formulated covering the following areas: description of biopsy procedure, overarching clinical design, patient characteristics, tissue handling and processing, quality control, histopathology, transcriptomic analyses and single-cell technologies.

Conclusions These PtC provide guidance on how research involving synovial tissue should be reported to ensure a better evaluation of results by readers, reviewers and the broader scientific community. We anticipate that these PtC will enable the field to progress in a robust and transparent manner over the coming years.

\section{INTRODUCTION}

Analyses of synovial tissue (ST) at both cellular and molecular levels offer a promising approach for personalised therapy in rheumatic diseases. ST analysis may also advance understanding of disease pathophysiological mechanisms and permit identification of potential therapeutic targets. ${ }^{1-3}$ Moreover, new developments in single cell methodologies are driving innovation and demand for ST-based studies. ${ }^{4-6}$ Methods to obtain ST, namely synovial biopsy (SB) procedures, are becoming more acceptable to patients and have been performed with increasing frequency over recent years for both clinical and translational research purposes. This is due in part to the introduction of ultrasound (US) guidance enabling minimally invasive approaches that have now been extensively validated in terms of safety, tolerability and tissue yield. ${ }^{7-11}$

However, the recent increase in numbers of studies using ST as a source of scientific material also raises questions in terms of interpretability and generalisability. Previous efforts have been initiated by the Outcome Measures in Rheumatology (OMERACT) group and the European Alliance of Associations for Rheumatology (EULAR) Synovitis Study Group (ESSG) in providing guidance on harmonisation of ST analysis procedures across centres for both clinical practice and research. ${ }^{12-16}$ Nevertheless, minimal requirements for reporting of SB procedures and handling methods of ST remain to be defined. Both reliability and validity of results in the field rely critically on tissue quality and processing. Moreover, selection of patients, methods of retrieval (as well as location within the joint), experience of the operator, handling and analysis methods and quality of the tissue have potential to affect the final research outcome. Therefore, there is an unmet need for evidence and consensus-based points to consider (PtC) defining minimum reporting requirements that could ensure interpretability of the research. Complete and accurate reporting will allow the reader to detect potential biases in the study (internal validity) and to assess the generalisability and applicability of the results (external validity). In this context, the aim of this work was to formulate the EULAR PtC for minimal reporting requirements in ST clinical practice and research in rheumatology.

\section{METHODS}

From December 2020 to May 2021, a steering committee composed of the conveners (ANalso fellow-and AF) and the senior and junior 


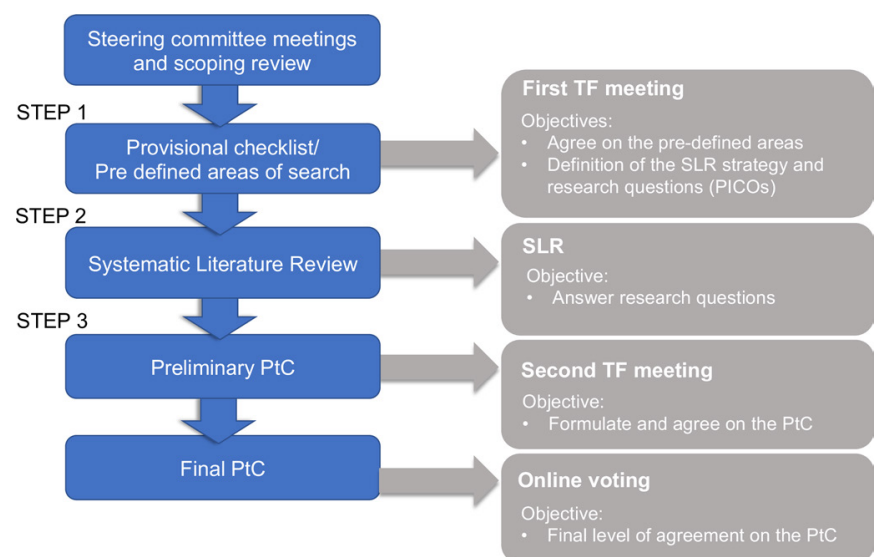

Figure 1 Project framework. PICO, population, intervention, comparison and outcomes; PtC, points to consider; SLR, systematic literature review; TF, task force.

methodologists (M-AD'A and FC) led a multidisciplinary task force following the 2014 updated EULAR standardised operating procedures. ${ }^{17}$ The task force included in total 25 members (including the steering committee) from 10 countries, composed of 19 rheumatologists ( 2 of them also representing the Emerging EULAR Network), 1 translational immunologist and 2 pathologists alongside one allied health professional and two patient representatives. Two virtual meetings of the task force were held, one in December 2020 and one in May 2021. During the first task force meeting, research questions pertaining to the project were formulated. The fellow (AN), guided by the methodologists, performed an systematic literature review (SLR), gathering articles on ST biopsy procedures, their tolerance and outcomes, tissue handling and randomisation, tissue quality control and tissue outcomes. The SLR is published separately, and it forms an integral part of the project.

During the second task force meeting, the results of the SLR were presented and discussed, leading to the formulation of $\mathrm{PtC}$ based on evidence and expert opinion. Every statement was presented, iteratively discussed and voted on (informal voting). The level of evidence (LoE) supporting each statement was assigned according to the Oxford Centre for Evidence Based Medicine 2011 Levels of Evidence. ${ }^{18}$ Of note, an LoE of five corresponds to expert opinion and an $\mathrm{LoE}$ of four corresponds to case-control studies. Finally, each task force member anonymously indicated their level of agreement (LoA) with each $\mathrm{PtC}$ online (Numerical Rating Scale ranging from $0={ }^{\prime}$ completely disagree' to $10=$ 'completely agree'). The aspects emerging during discussion that required further evidence were integrated in the research agenda. All these steps are summarised in figure 1. The final manuscript was reviewed and approved by all task force members, followed by verification by the EULAR Executive Committee.

\section{RESULTS}

Three overarching principles (OP) and nine $\mathrm{PtC}$ were formulated (table 1). All OP and PtC were approved after one round of hand raised voting during the task force meeting and one round of online voting after the task force meeting. The mean LoAs were higher or equal to 9 , with a percentage of votes above $8 / 10$ of $100 \%$ for most of the OP and PtC. LoA was reported in table 1. The LoE was 4 or 5 for all PtCs. The PtC is intended to provide guidance on how research involving ST should be reported in the following areas: biopsy procedures, study design, patients and disease characteristics, handling and processing methods of tissue, quality control, histological analysis, molecular analysis and single cell technologies. The target population was identified as rheumatologists, pathologists and scientists (eg, computational biologists, translational immunologists, molecular scientists), using or involved in research on ST. The target users were defined as physicians and allied health professionals (eg, physiotherapists and specialist nurses), patient research partners and patient charities and organisations, reviewers, journal editors, scientific societies and OMERACT, pharmaceutical industry, biopsy device manufacturers, and the enhancing the quality and transparency of health research network.

\section{Overarching principles}

OP-1: Synovial biopsies (single and sequential), performed in aseptic conditions, are safe, well tolerated and can be performed for both clinical and research purposes

SB is performed in both clinical and research settings across numerous centres in Europe. The body of evidence suggesting that the technique is safe and well tolerated has grown over the years, and the safety of the procedure is now well established. $^{781011 \text { 19-23 }}$ The task force emphasised that this applies to both single and sequential biopsies. ${ }^{11} 20$

OP-2: In both clinical and research settings, synovial biopsies should be guided by imaging techniques. Arthroscopy and ultrasonography are the preferred techniques to guide synovial biopsies

The task force strongly felt that SB should no longer be performed without imaging guidance. This is justified by the fact that blind needle biopsy (NB) procedures retrieve less graded tissue than guided techniques. ${ }^{24}$ The most commonly used imaging techniques to guide synovial biopsies are US-guided NB, US-guided portal and forceps and arthroscopy. CT and MRI guidance are not used commonly and therefore cannot be recommended.

\section{OP-3: US or arthroscopy can be used to guide the SB without} affecting the tolerability of the procedure or the minimal required tissue for meaningful analysis

While the number of graded ST fragments/total number of ST fragments does not differ with US and arthroscopic guided biopsy, the quantity and quality of RNA retrieved was superior with arthroscopy in a study comparing the tissue outputs of different techniques. ${ }^{24}$ Nevertheless, all techniques allow retrieval of a sufficient quantity of ST for meaningful analysis. Short-term and long-term tolerance is satisfactory with all guided techniques in terms of Visual Analogue Scale pain, swelling and stiffness for both small and large joints, with no difference reported between techniques in a study of over 500 procedures. ${ }^{11}$

\section{Points to consider}

PtC-1: The details of the biopsy procedure should be reported in every study. This should include non-exhaustively:

- Exclusion criteria for biopsy.

- Target joint(s) and recess.

- Intra-articular steroids in the previous 4 weeks or during the procedure.

- Technique used (type and size of biopsy retrieval device).

- Machine/probe for US-guided biopsies, arthroscopic equipment.

- Adverse events.

- Operator's experience and training.

Among the 26 manuscripts retrieved by the supporting SLR reporting on biopsy procedures, details of the procedure were very heterogeneously reported. For instance, exclusion criteria 
Table 1 Overarching principles and points to consider for minimal reporting requirements in synovial tissue clinical practice and research in rheumatology, with levels of evidence (LoE) and levels of agreement (LoA)

\begin{tabular}{|c|c|}
\hline Overarching principles & $\begin{array}{l}\text { LoA mean }(\mathrm{SD}) ; \\
\% \text { of votes } \geq 8 / 10\end{array}$ \\
\hline $\begin{array}{l}\text { 1. Synovial biopsies (single and sequential), performed in aseptic conditions, are safe, well-tolerated and can be performed for both clinical and research } \\
\text { purposes. }\end{array}$ & $9.77(0.53), 100 \%$ \\
\hline $\begin{array}{l}\text { 2. In both clinical and research settings, synovial biopsies should be guided by imaging techniques. Arthroscopy and ultrasound are the preferred } \\
\text { techniques to guide synovial biopsies. }\end{array}$ & $9.71(0.56), 100 \%$ \\
\hline $\begin{array}{l}\text { 3. Ultrasound or arthroscopy can be used to guide the synovial biopsy without affecting the tolerability of the procedure or the minimal required tissue } \\
\text { for meaningful analysis. }\end{array}$ & $9.14(0.96), 83.6 \%$ \\
\hline \multicolumn{2}{|l|}{ Points to consider } \\
\hline $\begin{array}{l}\text { 1. The details of the biopsy procedure should be reported in every study. This should include non-exhaustively: } \\
\text { Exclusion criteria for biopsy } \\
\text { Target joint(s) and recess } \\
\text { Intra-articular steroids in the previous } 4 \text { weeks or during the procedure } \\
\text { Technique used (type and size of biopsy retrieval device) } \\
\text { Machine/probe for ultrasound guided biopsies and arthroscopic equipment } \\
\text { Adverse events } \\
\text { Operator's experience and training (noting that no minimal training requirements are yet defined). (LoE 5) }\end{array}$ & $9.38(0.80), 100 \%$ \\
\hline $\begin{array}{l}\text { 2. Overarching clinical study design, including aspects related to participant disease characteristics and treatments, must be defined in order to evaluate } \\
\text { the generalisability and validity of the outcome. (LOE 5) }\end{array}$ & $9.81(0.51), 100 \%$ \\
\hline $\begin{array}{l}\text { 3. Conventional patient disease activity measures, disease stage and treatment should be described in order to evaluate the generalisability and validity } \\
\text { of the outcome. (LoE 5) }\end{array}$ & 9.45 (1.19), $95 \%$ \\
\hline $\begin{array}{l}\text { 4. Clinical and contemporary imaging characteristics of the biopsied joints should be described in order to evaluate the generalisability and validity of } \\
\text { the outcome. (LoE 4) }\end{array}$ & 8.95 (1.28), $90.5 \%$ \\
\hline $\begin{array}{l}\text { 5. Tissue handling and processing methods must be described in order to ensure reproducibility, including numbers and size of fragments allocated } \\
\text { randomly to each analytic. (LoE 4) }\end{array}$ & $9.10(1.64), 90.5 \%$ \\
\hline 6. Method and results of tissue quality assessment should be reported, including the percentage of graded tissue. (LoE 5) & $9.33(1.06), 90.5 \%$ \\
\hline $\begin{array}{l}\text { 1. When histological or immunohistological analysis is performed, the scoring or analysis system should be defined including: } \\
\text { Representative images } \\
\text { Reference to original publication for validated scoring systems only } \\
\text { Digital analysis software used, including version numbers of platforms } \\
\text { Immunohistological staining protocol, including antibody sources and clones } \\
\text { Area assessed and sampling strategy } \\
\text { Numbers of observers and intra- and inter-observer variability. (LoE 5) }\end{array}$ & $9.48(0.75), 100 \%$ \\
\hline 8. Methods of extraction and quantification should be defined, and purity, quantity and quality of DNA/RNA should be reported (LoE 5). & $9.67(0.58), 100 \%$ \\
\hline $\begin{array}{l}\text { 1. In case of single cell analysis, methods used and quality outcomes should be detailed, including: } \\
\text { Methods of tissue or cell preservation } \\
\text { Methods of tissue dissociation } \\
\text { Percentage of viable cells } \\
\text { Percentage of mitochondrial gene expression seen in the sequenced cells and the threshold chosen for analysis } \\
\text { (LoE 4) }\end{array}$ & $9.71(0.56), 100 \%$ \\
\hline
\end{tabular}

LoA, Level of agreement; LoE, Level of Evidence; SD, Standard deviation.

for biopsy and intra-articular treatments in the previous 4 weeks or during the procedure (intra-articular steroids) were reported in less than $10 \%$ of the manuscripts, while the target joint(s) and recess, technique used, and equipment were more frequently reported ( $>75 \%$ of included studies). Adverse events were reported in only $20 \%$ of the manuscripts and none reported operator's experience.

Based on these results, the task force developed a nonexhaustive list of elements pertaining to the procedure itself that should be mentioned in every study involving SB. Although minimal training requirements for SB are not yet defined, operator's experience and training should be reported in every study. Of note, a standardised training model for US-guided, minimally invasive SB procedures in large and small joints constitutes another EULAR task force initiative. ${ }^{25}$ In addition, depending on the study design, a description of patient tolerability of the procedure is desirable.
PtC-2: Overarching clinical study design, including aspects related to participant disease characteristics and treatments, must be defined in order to evaluate the generalisability and validity of the outcome This point refers to the study design, defined a priori when the study framework is elaborated by authors. It is known that treatments and disease phenotype can affect ST outcomes in terms of histopathology and transcriptomics especially in inflammatory arthritis. ${ }^{1426-32}$ Therefore, the task force recommends that aspects pertaining to study design, including participants, disease characteristics (including fulfilment of classification criteria) and treatments, should always be reported in manuscripts.

\section{PtC-3: Conventional patient disease activity measures, disease} stage and treatment should be described in order to evaluate the generalisability and validity of the outcome

This point refers specifically to outcome measures and characteristics of the patients included in the study that should always be reported. In the SLR, $100 \%$ of studies reported patient 
demographics and diagnosis, but only $62 \%$ reported clinical data, such as disease activity and current therapy. More specifically, disease activity measures should be outlined, including Disease Activity Score $28 \mathrm{C}$ reactive protein or erythrocyte sedimentation rate (ESR), Clinical Disease Activity Index or Simple Disease Activity Index for rheumatoid arthritis or other measures depending on the rheumatic disease under evaluation. Disease duration and conventional synthetic, targeted synthetic or biologic disease-modifying antirheumatic drugs should be reported.

PtC-4: Clinical and contemporary imaging characteristics of the biopsied joints should be described in order to evaluate the generalisability and validity of the outcome

First, the task force felt that clinical assessment of the biopsied joint including swelling should be reported. In the context of US guided SB, the US synovitis grade of the target joint is typically assessed. Surprisingly, these data were described in only $36 \%$ of the manuscripts describing US-guided SB in the SLR. The task force emphasised that the US grade of the synovitis in B mode and Doppler can affect tissue quality and outcomes, ${ }^{7} 1533$ and therefore, recommends that contemporary imaging characteristics of the biopsied joint are described. In addition, when available, radiographic aspects should be described and when the erosive status of the biopsied joint is known, this information should be provided.

PtC-5: Tissue handling and processing methods must be described in order to ensure reproducibility, including numbers and size of fragments allocated to each analytic.

Our SLR retrieved numerous studies looking into intra-articular variability of tissue outcomes and sampling error. ${ }^{15}$ 34-39 More specifically, immune cell infiltrate, immunohistochemistry, cytokine mRNA and T cell repertoire displayed little or no difference when retrieved in different parts of large joints. ${ }^{36-38}$

Of interest, studies assessing sampling error showed that a minimum of 4 tissue fragments provided a reliable sample with $10 \%$ sampling error for small joint histopathological analysis, ${ }^{15}$ while 4-7 tissue fragments were required to detect a twofold change with a $25 \%$ sampling error in PCR in large joints ${ }^{34}$ and the percentage mean difference for the staining of immunohistochemical cellular markers decreases below $\pm 10 \%$ when a minimum of eight samples are considered in the evaluation. ${ }^{39}$ In addition, a minimum of 6 fragments and the assessment of an area of tissue of minimum $2.5 \mathrm{~mm}^{2}$ were deemed necessary to ensure representativity of histological analysis. ${ }^{40} 41$ In this context, the task force recommends that authors report data pertaining to tissue handling and processing, including numbers and size of fragments allocated to each analytic.

\section{PtC-6: Method and results of tissue quality assessment should be reported, including the percentage of graded tissue}

Among the 26 studies included in the SLR, only 17 reported having controlled the tissue quality during their study (65\%). The task force felt it was absolutely necessary for a quality control to be performed and reported by authors in manuscripts in order to ensure reliability and reproducibility of the results. When histopathological analysis is performed, the percentage of tissue presenting with a typical ST structure and an intact lining layer or positive CD68 staining should be reported. $^{71516}$
PtC-7: When histological or immunohistological analysis is performed, the scoring or analysis system should be defined including

- Representative images.

- Reference to original publication for validated scoring systems only.

- Digital analysis software, including version numbers of platforms used.

- Immunohistological staining protocol, including antibody sources and clones.

- Area assessed and sampling strategy.

- Number of observers and intraobserver and interobserver variability.

Since numerous studies assess histological aspects of the tissue, it was felt important by the task force to formulate a PtC related to histological scoring. More specifically, several aspects were deemed mandatory by the task force, such as describing staining protocols and antibodies sources and clones, providing representative images illustrating the findings and describing area assessed and sampling strategy. In the manuscripts included in the SLR, scoring systems were rarely described and chains of references to previous publications, but not the original scoring system, were often observed. Subsequently, the task force recommended that only the original publication describing the scoring system should be cited. The interobserver and intraobserver variability for histological analysis was similarly rarely described $(n=4 / 26$ publications, 15\%) and should always be reported for studies using scoring by observers.

PtC-8: Methods of extraction and quantification should be defined and purity, quantity and quality of DNA/RNA should be reported Although no study specifically assessed the difference in outcomes arising from tissues yielding DNA or RNA of high versus poor quality (measured by the RNA integrity number for RNA), it was considered important by the task force members that such information should be reported in every manuscript. It is indeed anticipated that poor quality RNA, if used for RNA sequencing, will provide unreliable results. In addition, it has been noted in the SLR that such information was very rarely reported in the analysed publications (two out eight publications looking at molecular aspects of ST (25\%)).

PtC-9: In case of single cell analysis, methods used and quality outcomes should be detailed, including

- Methods of tissue or cell preservation.

- Methods of tissue dissociation.

- Percentage of viable cells recovered or analysed.

- Percentage of mitochondrial gene expression seen in the sequenced cells and the threshold chosen for analysis.

- If sorting is used, the strategy used and purity of sorted cells. The recent development of single cell technologies has also raised methodological challenges. Of interest, the methods of tissue conservation or dissociation can influence the tissue outcome. In a study from Donlin et al, mechanical versus mechanical and enzymatic ST dissociation methods have been compared, showing that the latter retrieved a higher total cell count per gram of tissue, a higher viable cell count and a more representative number of cell subpopulations. In addition, they compared methods of tissue preservation, showing that cryopreserved samples retrieved similar numbers of viable cells and a similar variety of cell subpopulations to fresh samples. ${ }^{35}$ Therefore, the task force recommends that these elements are reported in every publication, in addition to other aspects related to 
quality, such as the percentage of viable cells and percentage of mitochondrial gene expression seen in the sequenced cells alongside parameters related to cell sorting methods, including flow cytometric staining protocols.

\section{DISCUSSION}

These are the first EULAR-endorsed PtC on ST research in rheumatology with the aim of them serving as a reference and checklist for clinicians and scientists involved in publishing, reviewing and reading manuscripts reporting ST research. They have been proposed by a multidisciplinary team of international experts in the field involving rheumatologists, translational researchers, methodologists and pathologists.

Our SLR retrieved several manuscripts, which were analysed from different perspectives. With respect to the OPs, we emphasised that the body of evidence on SB tolerability and safety is very reassuring for both single and sequential biopsies. In addition, the task force stated that SB should no longer be performed without imaging guidance, more specifically blind needle biopsies are no longer recommended. There is no preferred guiding technique between US or arthroscopy, since both allow retrieval of a sufficient quantity of tissue for meaningful analysis and are well tolerated. ${ }^{1124}$ Of interest, we assessed how comprehensively data relevant to study design, patients' characteristics, biopsy procedures, tissue handling, quality control and tissue outcomes were reported in the publications. In this regard, these $\mathrm{PtC}$ focus on specific areas requiring attention from authors when reporting their study results in order to ensure internal and external validity of the studies and generalisability. These PtCs are also proposed in an editor friendly document appearing as a checklist and provided in online supplemental material 1.

While conducting this work, we realised that the paucity of literature on clinical applications of tissue analysis did not allow the formulation of $\mathrm{PtC}$ dedicated to the clinical aspects. Indeed, although recent publications propose encouraging data for the use of SB for diagnosis, outcome prediction or disease management in clinical practice, the task force felt that these aspects should be included in the research agenda. ${ }^{242-44}$ One major limitation encountered in the development of these $\mathrm{PtC}$ was the scarcity of literature appraising the practical aspects of tissue retrieval, handling and analysis. Due to the paucity of evidence comparing methods or outcomes based on tissue handling, quality or analysis, most of these PtC rely on expert opinion. In

\section{Box 1 Research agenda}

\section{Research agenda}

- Minimal training requirement for ultrasound guided SB for physicians and allied health professionals.

- Impact of training on patient tolerability; tissue yield/quality/ outcomes.

- Influence of tissue handling and processing (fixation, standardised operating procedures for freezing in optimal cutting temperature (OCT), fixation, and freezing (and time to freezing) for subsequent live tissue/cell analysis) on tissue quality/outcome.

- Clinical practice: supportive data for diagnosis or prognosis or disease management.

- Risk of Bias tools for translational research.

- Tissues considered as best 'non-inflammatory' controls (eg, healthy subjects, meniscectomy surgery, traumatic arthritis, cadavers). this respect, it is noteworthy that the members of this task force acted as representatives of the most prominent centres working in the field of translational research in ST, including EULAR centres of excellence. Based on the SLR results and the inputs and discussion arising from the second task force meeting, other relevant items were incorporated in the research agenda (box 1).

In conclusion, these EULAR PtCs provide relevant guidance on minimal reporting requirements in ST research in Rheumatology. These first EULAR PtCs are intended to be disseminated and used by the broad research community, adding to previous initiatives from OMERACT and ESSG in order to allow the field of ST research to evolve in a robust and transparent manner in the future.

\section{Author affiliations}

${ }^{1}$ Institute of Infection, Immunity and Inflammation, University of Glasgow College of Medical Veterinary and Life Sciences, Glasgow, UK

${ }^{2}$ Université Paris-Saclay, UVSQ, Inserm U1173, Infection et Inflammation, Laboratory of Excellence Inflamex, Montigny-Le-Bretonneux, France

${ }^{3}$ Rheumatology Department, AP-HP, Boulogne-billancourt, Paris, France

${ }^{4}$ UOC di Reumatologia, Fondazione Policlinico Universitario Agostino Gemelli IRCSS, Università Cattolica del Sacro Cuore, Rome, Italy

${ }^{5}$ Internal Medicine and Nephrology Unit, Department of Clinical Medicine Life Health and Environmental Sciences, University of L'Aquila, L'Aquila, Italy

${ }^{6}$ Department of Pathology, Department of Anatomical Pathology, Central University Hospital of Liege, Liege, Belgium

${ }^{7}$ Rheumatology Patient Group, University Hospitals Birmingham NHS Foundation

Trust, Birmingham, UK

${ }^{8}$ Department of Pathology and Laboratory Medicine, University of Rochester Medical

Center, Rochester, New York, USA

${ }^{9}$ Arthritis Unit, Rheumatology Dpt, IDIBAPS, Barcelona, Spain

${ }^{10}$ Joint and Bone Research Unit. Rheumatology Dept, Hospital Universitario

Fundación Jiménez Díaz, Madrid, Spain

${ }^{11}$ Department of Medicine, San Salvatore Hospital, L'Aquila, Italy

${ }^{12}$ Pôle de Recherche en Rhumatologie, Institut de Recherche Expérimentale et

Clinique, Université catholique de Louvain Secteur des sciences de la santé, Bruxelles, Belgium

${ }^{13}$ Pôle de Recherche en Rhumatologie, Institut de Recherche Expérimentale et

Clinique, Cliniques universitaires Saint-Luc, Bruxelles, Belgium

${ }^{14}$ Serviço de Reumatologia, Centro Hospitalar Universitário Lisboa Norte, Instituto de Medicina Molecular, Lisboa, Portugal

${ }^{15}$ Department of Rheumatology, Bone and Joint Research Unit, Odense

Universitetshospital, Odense, Denmark

${ }^{16}$ Universidad Autónoma de Madrid, Madrid, Spain

${ }^{17}$ Translational Immunology Research Laboratories (LaRIT), Division of Rheumatology, Fondazione IRCCS Policlinico San Matteo, Pavia, Italy

${ }^{18}$ Rheumatology Research Group and Research into Inflammatory Arthritis

Centre Versus Arthritis, Institute of Inflammation and Ageing, NIHR Birmingham

Biomedical Research Center, University Hospitals Birmingham NHS Foundation Trust, Birmingham, UK

${ }^{19}$ Universitario Fundación Jiménez Díaz, IIS Fundación Jiménez Díaz, Rheumatology,

Universidad Autónoma de Madrid, Madrid, Spain

${ }^{20}$ Centre for Arthritis and Rheumatic Disease, University College Dublin, Dublin, Ireland

${ }^{21}$ The Conway Institute, St Vincent's University Hospital, Dublin, Ireland

${ }^{22}$ Centre for Experimental Medicine and Rheumatology, Barts and The London Schoo of Medicine and Dentistry William Harvey Research Institute, London, UK

${ }^{23}$ Patient Research Partners, Antwerp Province, Antwerpen, Belgium

${ }^{24}$ Amsterdam Rheumatology and Immunology Center, Department of Clinical Immunology and Rheumatology, Amsterdam University Medical Centres, Amsterdam, Noord-Holland, The Netherlands

Twitter Søren Andreas Just @JustSoren and Andrew Filer @A_Filer

Contributors All authors formulated the recommendation. All authors contributed to and finally approved the current manuscript.

Funding This work was funded by EULAR (SCI020).

Competing interests $A N$ has received consulting and/or speaker's fees from UCB, CHUGAl, BMS all unrelated to this manuscript. FC has received consulting and/or speaker's fees from Lilly, Novartis and UCB, all unrelated to this manuscript. $M-A D$ 'A has received consulting and/or speaker's fees from Lilly, Novartis, AbbVie, BMS, Pfizer, Galapagos, and UCB, all unrelated to this manuscript. AF has received consulting and/or speaker's fees from Janssen, GSK, Abbvie, Galapagos and receives research funding from Janssen, GSK, Mestag, Roche and Celsius, all unrelated to this manuscript. EN has received consulting and/or speaker's fees from Roche, BMS, 
UCB, Lilly Celgene GmbH, all unrelated to this manuscript. SA has received research funding by Abbvie, Pfizer, BMS and GSK and has received consulting and/or speaker's fees from Abbvie, Pfizer, BMS, Galapagos, Novartis, Janssen and Lilly all unrelated to this manuscript. JEF has received research funding and/or speaker's fees from Abbvie, Ache, Biogen, Janssen, Lilly, MSD, Novartis, Pfizer, UCB, all unrelated to this manuscript. SWT received research funding and/or speaker's fees from AbbVie, Arthrogen/MeiraGTx, AstraZeneca, BMS, Celgene, Galapagos, GSK, MSD, Pfizer, Roche, Sanofi-Genzyme, all unrelated to this manuscript. VCR has received research funding and non-financial support from Merck Sharp and Dohme; personal fees and non-financial support from Pfizer and Janssen; non-financial support from Lilly and Roche, outside the submitted work. MM Supported by the National Institute of Health Research (NIHR) Birmingham Biomedical Research Centre at the University Hospitals Birmingham NHS Foundation Trust and the University of Birmingham. The author(s) views unrelated to the NIHR or the department of Health and Social Care.

Patient consent for publication Not applicable.

Ethics approval This study does not involve human participants.

Provenance and peer review Not commissioned; externally peer reviewed.

Supplemental material This content has been supplied by the author(s). It has not been vetted by BMJ Publishing Group Limited (BMJ) and may not have been peer-reviewed. Any opinions or recommendations discussed are solely those of the author(s) and are not endorsed by BMJ. BMJ disclaims all liability and responsibility arising from any reliance placed on the content. Where the content includes any translated material, BMJ does not warrant the accuracy and reliability of the translations (including but not limited to local regulations, clinical guidelines, terminology, drug names and drug dosages), and is not responsible for any error and/or omissions arising from translation and adaptation or otherwise.

\section{ORCID iDs}

Aurélie Najm http://orcid.org/0000-0002-6008-503X

Félicie Costantino http://orcid.org/0000-0002-1449-959X

Alessia Alunno http://orcid.org/0000-0003-1105-5640

Juan D Canete http://orcid.org/0000-0003-2606-0573

Francesco Carubbi http://orcid.org/0000-0003-1958-5136

Patrick Durez http://orcid.org/0000-0002-7156-2356

João Eurico Fonseca http://orcid.org/0000-0003-1432-3671

Raquel Largo http://orcid.org/0000-0001-6525-2944

Costantino Pitzalis http://orcid.org/0000-0003-1326-5051

Vasco C Romão http://orcid.org/0000-0002-5603-9436

Douglas J Veale http://orcid.org/0000-0003-2802-4971

Maria-Antonietta D'Agostino http://orcid.org/0000-0002-5347-0060

Andrew Filer http://orcid.org/0000-0001-8164-6249

\section{REFERENCES}

1 Orr C, Vieira-Sousa E, Boyle DL, et al. Synovial tissue research: a state-of-the-art review. Nat Rev Rheumatol 2017;13:463-75.

2 Humby FC, Al Balushi F, Lliso G, et al. Can synovial pathobiology integrate with current clinical and imaging prediction models to achieve personalized health care in rheumatoid arthritis? Front Med 2017:4:41.

3 Johnsson H, Najm A. Synovial biopsies in clinical practice and research: current developments and perspectives. Clin Rheumatol 2021;40:2593-600.

4 Alivernini S, MacDonald L, Elmesmari A, et al. Distinct synovial tissue macrophage subsets regulate inflammation and remission in rheumatoid arthritis. Nat Med 2020;26:1295-306

5 Croft AP, Campos J, Jansen K, et al. Distinct fibroblast subsets drive inflammation and damage in arthritis. Nature 2019;570:246-51.

6 Zhang F, Wei K, Slowikowski K, et al. Defining inflammatory cell states in rheumatoid arthritis joint synovial tissues by integrating single-cell transcriptomics and mass cytometry. Nat Immunol 2019;20:928-42.

7 Kelly S, Humby F, Filer A, et al. Ultrasound-Guided synovial biopsy: a safe, welltolerated and reliable technique for obtaining high-quality synovial tissue from both large and small joints in early arthritis patients. Ann Rheum Dis 2015;74:611-7.

8 Najm A, Orr C, Heymann M-F, et al. Success rate and utility of ultrasound-guided synovial biopsies in clinical practice. J Rheumatol 2016;43:2113-9.

9 Romão VC, Polido-Pereira J, Barros R, et al. Efficacy, safety, and sample quality of ultrasound-guided synovial needle biopsy in clinical practice and research: a prospective observational study. Arthritis Care Res 2020;72:1497-505.

10 Lazarou I, D'Agostino M-A, Naredo E, et al. Ultrasound-Guided synovial biopsy: a systematic review according to the OMERACT filter and recommendations for minimal reporting standards in clinical studies. Rheumatology 2015;54:1867-75.

11 Just SA, Humby F, Lindegaard $\mathrm{H}$, et al. Patient-Reported outcomes and safety in patients undergoing synovial biopsy: comparison of ultrasound-guided needle biopsy, ultrasound-guided portal and forceps and arthroscopic-guided synovial biopsy techniques in five centres across Europe. RMD Open 2018;4:e000799.

12 Bresnihan B, Cunnane G, Youssef $\mathrm{P}$, et al. Microscopic measurement of synovial membrane inflammation in rheumatoid arthritis: proposals for the evaluation of tissue samples by quantitative analysis. Br $J$ Rheumatol 1998;37:636-42.
13 Bresnihan B, Pontifex E, Thurlings RM, et al. Synovial tissue sublining CD68 expression is a biomarker of therapeutic response in rheumatoid arthritis clinical trials: consistency across centers. J Rheumatol 2009;36:1800-2.

14 Bresnihan B, Baeten D, Firestein GS, et al. Synovial tissue analysis in clinical trials. J Rheumatol 2005;32:2481-4.

15 Humby F, Kelly S, Hands R, et al. Use of ultrasound-guided small joint biopsy to evaluate the histopathologic response to rheumatoid arthritis therapy: recommendations for application to clinical trials. Arthritis Rheumatol 2015;67:2601-10.

16 Najm A, Le Goff B, Orr C, et al. Standardisation of synovial biopsy analyses in rheumatic diseases: a consensus of the EULAR synovitis and OMERACT synovial tissue biopsy groups. Arthritis Res Ther 2018;20:265.

17 van der Heijde D, Aletaha D, Carmona L, et al. 2014 update of the EULAR standardised operating procedures for EULAR-endorsed recommendations. Ann Rheum Dis 2015;74:8-13.

18 CEBM-Levels-of-Evidence-2.1.pdf. Available: https://www.cebm.net/wp-content/ uploads/2014/06/CEBM-Levels-of-Evidence-2.1.pdf [Accessed 12 Jul 2021].

19 Romao VC, Polido-Pereira J, Barros R. FRI0678 ultrasound-guided synovial needle biopsy: single center experience of an emerging, minimally invasive technique in clinical practice and research. Ann Rheum Dis 2017;76:746-7.

20 Kane D, Veale DJ, FitzGerald 0 , et al. Survey of arthroscopy performed by rheumatologists. Rheumatology 2002;41:210-5.

21 Dyke B, Maybury M, Alivernini S. Survey of Minimally-Invasive Ultrasound-Guided Synovial Biopsy Performed at Rheumatology Centres [abstract]. Arthritis Rheumatol 2020;72 https://acrabstracts.org/abstract/survey-of-minimally-invasive-ultrasoundguided-synovial-biopsy-performed-at-rheumatology-centres/

22 Humby F, Kelly S, Bugatti S, et al. Evaluation of Minimally Invasive, Ultrasoundguided Synovial Biopsy Techniques by the OMERACT Filter--Determining Validation Requirements. J Rheumatol 2016;43:208-13.

23 Meric de Bellefon L, Durez P, Galant C, et al. OP0121 Safety, Tolerability and Feasibility of Minimally Invasive Ultrasound-Guided Synovial Biopsy of Wrist and Metacarpophalangeal Joints - An Ultrasound Follow-Up Study. Ann Rheum Dis 2016;75:101.1-101.

24 Humby F, Romão VC, Manzo A, et al. A multicenter retrospective analysis evaluating performance of synovial biopsy techniques in patients with inflammatory arthritis: arthroscopic versus ultrasound-guided versus blind needle biopsy. Arthritis Rheumatol 2018;70:702-10.

25 Möller I. Sp0211 Development of a Standardized Training Model for UltrasoundGuided Synovial Biopsy"s in Small and Large Joints. Annals of the Rheumatic Diseases 2019;78:65.

26 Lindberg J, Wijbrandts CA, van Baarsen LG, et al. The gene expression profile in the synovium as a predictor of the clinical response to infliximab treatment in rheumatoid arthritis. PLoS One 2010:5:e11310.

27 Rivellese F, Humby F, Bugatti S, et al. B cell synovitis and clinical phenotypes in rheumatoid arthritis: relationship to disease stages and drug exposure. Arthritis Rheumatol 2020;72:714-25.

28 Chatzidionysiou K, Engström M, Af Klint E. Significant decrease of T-cells but not macrophages in the synovium of patients with active rheumatoid arthritis after treatment with tocilizumab. Ann Rheum Dis 2018;77:891.

29 Ducreux J, Durez P, Galant C. Global molecular effects of tocilizumab therapy in rheumatoid arthritis synovium: molecular effects of tocilizumab therapy. Arthritis \& Rheumatology 2014;66:15-23.

30 Orr C, Najm A, Biniecka M, et al. Synovial immunophenotype and Anti-Citrullinated peptide antibodies in rheumatoid arthritis patients: relationship to treatment response and radiologic prognosis. Arthritis Rheumatol 2017;69:2114-23.

31 De Groof A, Ducreux J, Humby F, et al. Higher expression of TNF $\alpha$-induced genes in the synovium of patients with early rheumatoid arthritis correlates with disease activity, and predicts absence of response to first line therapy. Arthritis Res Ther 2016;18.

32 Pirbuccus F, Galant C, Toukap AN. Differences in histological scores and histoclinical correlations in AcpA versus ACPA+ rheumatoid arthritis patients. Arthritis Rheum 2016;68:747-8.

33 Humby FC. Synovial tissue sampling in Rheumatological Practice-Past developments and future perspectives. Front Med 2019;6.

34 Boyle DL, Rosengren S, Bugbee W, et al. Quantitative biomarker analysis of synovial gene expression by real-time PCR. Arthritis Res Ther 2003:5:R352-60.

35 Donlin LT, Rao DA, Wei K, et al. Methods for high-dimensional analysis of cells dissociated from cryopreserved synovial tissue. Arthritis Res Ther 2018;20:139.

36 Smeets TJM, Barg EC, Kraan MC, et al. Analysis of the cell infiltrate and expression of proinflammatory cytokines and matrix metalloproteinases in arthroscopic synovial. biopsies: comparison with synovial samples from patients with end stage, destructive rheumatoid arthritis. Ann Rheum Dis 2003;62:635-8.

37 Musters A, Klarenbeek PL, Doorenspleet ME, et al. In rheumatoid arthritis, synovitis at different inflammatory sites is dominated by shared but patient-specific $T$ cell clones. The Journal of Immunology 2018;201:417-22.

38 Kirkham BW, Lassere MN, Edmonds JP, et al. Synovial membrane cytokine expression is predictive of joint damage progression in rheumatoid arthritis: a two-year prospective study (the damage study cohort). Arthritis Rheum 2006;54:1122-31. 
39 Scirè C, Epis O, Codullo V, et al. Immunohistological assessment of the synovial tissue in small joints in rheumatoid arthritis: validation of a minimally invasive ultrasoundguided synovial biopsy procedure. Arthritis Res Ther 2007;9:R101.

40 Dolhain RJ, Ter Haar NT, De Kuiper R, et al. Distribution of T cells and signs of T-cell activation in the rheumatoid joint: implications for semiquantitative comparative histology. Rheumatology 1998;37:324-30.

41 Kennedy TD, Plater-Zyberk C, Partridge TA, et al. Representative sample of rheumatoid synovium: a morphometric study. J Clin Pathol 1988;41:841-6.

42 Humby F, Durez P, Buch MH, et al. Rituximab versus tocilizumab in anti-TNF inadequate Responder patients with rheumatoid arthritis (R4RA): 16-week outcomes of a stratified, biopsy-driven, multicentre, open-label, phase 4 randomised controlled trial. Lancet 2021:397:305-17.

43 Alivernini S, Tolusso B, Petricca L, et al. Synovial features of patients with rheumatoid arthritis and psoriatic arthritis in clinical and ultrasound remission differ under antiTNF therapy: a clue to interpret different chances of relapse after clinical remission? Ann Rheum Dis 2017:76:1228-36

44 Alivernini S, Tolusso B, Gessi M, et al. Inclusion of synovial tissue-derived characteristics in a nomogram for the prediction of treatment response in treatment-naive rheumatoid arthritis patients. Arthritis Rheumatol 2021;73:1601-13. 